\title{
Vulnerability analysis toward river flooding in the Comal Watershed, Indonesia
}

\author{
Yunus Aris Wibowo ${ }^{1 *}$, Muh Aris Marfai ${ }^{2}$, Muhammad Pramono $\mathrm{Hadi}^{3}$,Lintang Ronggowulan ${ }^{4}$, and Puspita Indra \\ Wardhani ${ }^{1}$ \\ ${ }^{1}$ Geography Education Department, Universitas Muhammadiyah Surakarta, Indonesia \\ ${ }^{2}$ Geospatial Information Agency (BIG), Indonesia \\ ${ }^{3}$ Geography Faculty, Universitas Gadjah Mada, Indonesia \\ ${ }^{4}$ Geography Education Department, Universitas Sebelas Maret Surakarta, Indonesia
}

\begin{abstract}
River flooding is a disaster that almost every year hits the downstream Comal watershed. This incident resulted in material, psychological, and even casualties. Therefore, a vulnerability analysis is needed to reduce the impact of flooding. This study aims to analyze the vulnerability to river flooding in the downstream Comal Watershed area, Indonesia. Vulnerability variables used are social, economic, physical, and ecological (environmental) vulnerability following the Indonesian National Disaster Management Agency (BNPB) Regulation 2012. Data were obtained from government agencies and interpretation of SPOT 5 satellite imagery. Data analysis were carried out using scoring and weighting. Moreover, the data classification were using the mean and standard deviation equations. The analysis showed that the vulnerability to river flooding in the Comal watershed area was dominated by a moderate vulnerable class of $10,832.15$ hectares $(49.69 \%)$ and distributed in 26 villages. Furthermore, the high level of vulnerability also covered a large area by $8,773.11$ hectares (40.24\%), and distributed across 29 villages. Therefore, proper river flooding mitigation planning with the characteristics of the area is needed.
\end{abstract}

\section{Introduction}

Flood is a phenomenon that annually hits most cities in the world. It can be triggered either by natural processes or by human activities. Natural processes include hydrometeorological hazards such as tropical cyclones, storms, and high rainfall, while human activities include dam failure and land conversion [1,2]. The global impact of flooding is a disruption of life and the economy in exposed areas $[3,4]$. Furthermore, it is influenced by the intensity and frequency of hazards/threats and vulnerabilities in flood-prone areas.

The basic concept of vulnerability is a broad and appropriate framework for considering the underlying and indirect causes of disaster events. Vulnerability is simply a condition of a society that makes them potentially impacted by adverse hazards. Vulnerability is seen as a result of danger and is determined by the variables of vulnerability, sensitivity, and consequences of potential hazards [5-8]. The vulnerability can be seen from various variables that can increase the level of vulnerability to a hazard. [9-13] mentions four vulnerability variables, namely social, economic, physical, and ecological/environmental vulnerability.

Vulnerability variables always have different risk components depending on the types and characteristics of the vulnerability variables [6]. Risk components are all objects, individuals, animals, activities, and processes that can be negatively impacted by harmful natural phenomena, either directly or indirectly [13]. The frequency of exposure to hazards/threats tends to increase the community's vulnerability because there will gradually be a weakening of the capacity either physically, socially, or economically. In the long term, this can decrease coping capacity and lead to community resilience to disasters.

The Comal River flood disaster is a natural phenomenon that annually occurs during the rainy season downstream of Comal Watershed. It can be categorized as a severe disaster because it has caused many casualties and losses. One of the worst flood disasters in the last 20 years occurred from January to February 2014. Based on data recorded by the Regional Disaster Management Agency and the Social, Department of Social, Labor, and Transmigration Service of Pemalang Regency, floods in 2014 resulted in 66,810 residents displaced, tens of hectares of agricultural land were submerged, 16,259 houses were submerged, 53 of which were severely damaged with an estimated loss of Rp 35,000,000.00 for each house and three bridges in Longkeyang Village were broken. Therefore, flood disaster management measures are urgently needed in the Comal watershed area. One of the first steps in overcoming the flood disaster is to conduct vulnerability analysis of the downstream Comal watershed.

In line with the development of science and technology used in disaster analysis, several views have

\footnotetext{
* Corresponding author: yaw222@ums.ac.id
} 
emerged regarding the appropriate method for vulnerability analysis [14]. At least, there are two most popular approaches, namely the techno-scientific approach and the social approach [15-18]. The technoscientific approach focuses on physical variables and tends to neglect the indirect effects of disasters. Conversely, the social approach prioritizes human variables through a social process. This approach places human variables as the main focus to be saved in disaster management.

This study focused on analyzing the vulnerability of the area to river flooding in the Comal watershed, Indonesia. It is conducted by emphasizing social, economic, physical, and ecological (environmental) variables. The vulnerability analysis is carried out quantitatively with a spatial approach. These variables are selected with consideration to obtain comprehensive and reliable analysis results. Vulnerability analysis not only focuses on specific variables and direct impacts but also analyzes all variables of vulnerability that affect a region. Furthermore, the analysis is also conducted based on variables that may cause long-term or indirect impacts. Comprehensive vulnerability analysis can produce an accurate risk assessment and mitigation planning for flood disasters [19,20].

\section{Research method}
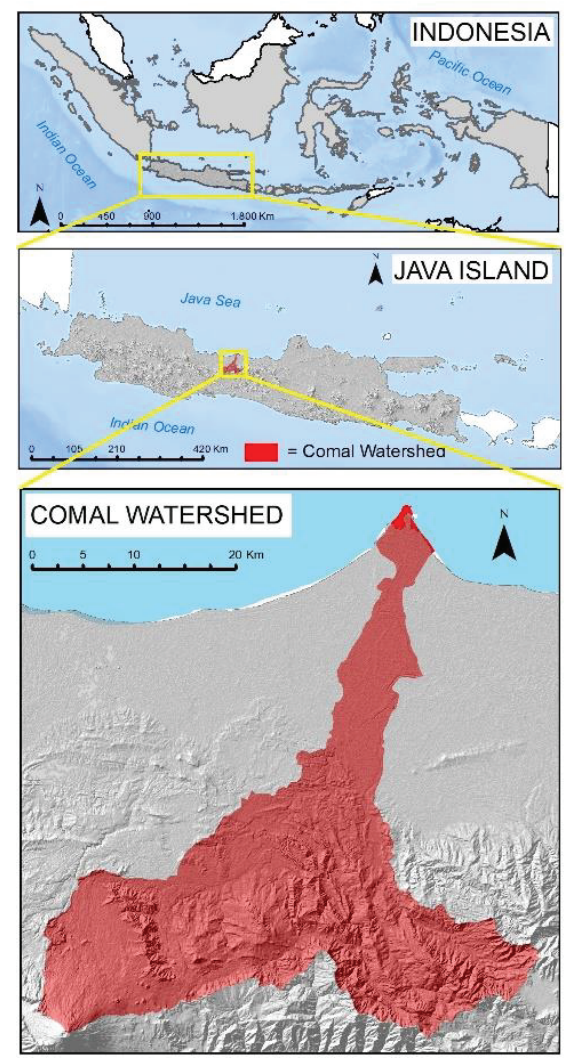

Figure 1. Study location

The downstream Comal watershed is located in Pemalang Regency, Central Java Province, Indonesia (Fig. 1). This watershed is one of the watersheds with a priority for handling in Indonesia. The priority includes land and forest rehabilitation, including reforestation, soil, and water conservation, whether carried out vegetatively, agronomically, structurally, and in management [21]. The Comal River flooding vulnerability level in the downstream Comal watershed is analyzed based on four physical, social, economic, and (ecology) environmental variables. Each vulnerability variable has a different weight depending on the level of fatality. Social variables weight $40 \%$, economic 25\%, physical 25\%, and ecology (environmental) $10 \%$ based on modification of [9]. Each variable consists of exposure parameters that reflect the vulnerability characteristics of each variable in the research location. Moreover, each variable consists of several parameters (element at-risk) that have a weight determined based on fatality level when exposed to hazards/threats. Element at-risk data were obtained from various official government sources and primary data analysis.

The unit of analysis in this research is the village area. This is done to obtain detailed results and to describe the vulnerability of the region. Furthermore, this research covers 59 villages from five sub-districts downstream of the Comal watershed. The analysis process is carried out by scoring based on the scoring guidelines from [9].

Vulnerability analysis begins with grouping the vulnerability parameters (element at-risk) of each vulnerability variable based on its class. Each parameter of vulnerability (element at-risk) is classified into five categories. The level is obtained from calculations using the mean and standard deviation equations.

Mean deviation $: \bar{x}=\frac{1}{n} \sum_{i=1}^{n} x_{i}$

Standard deviation $: S=\sqrt{\frac{1}{n-1} \sum_{i=1}^{n}\left(x_{i}-x\right)^{-2}}$

The next stage is scoring on each parameter of vulnerability (element at-risk) of each variable. The score given is very high $=5$, high $=4$, medium $=3$, low $=2$ and very low $=1$ (Table 1$)$. The score is multiplied by the weight of each risk component for each vulnerability variable. The multiplication results are added according to each vulnerability variable (social, economic, physical, and environmental). The total weight (score * weight of the risk component) on each variable of vulnerability (social, economic, physical, and environmental) is summed, and the results are used as the basis for determining the class of total vulnerability. The total vulnerability class is calculated by using the mean and standard deviation equations, such as determining the class of risk components/parameters for each vulnerability variable.

Table 1. The vulnerability levels, scores, and weights

\begin{tabular}{|c|c|c|}
\hline Classes & Score & Weights \\
\hline Very high & 5 & $4.2-5$ \\
\hline High & 4 & $3.4-4.2$ \\
\hline Moderate & 3 & $2.6-3.4$ \\
\hline Low & 2 & $1.8-2.6$ \\
\hline Very low & 1 & $<1,8$ \\
\hline
\end{tabular}

Source: Data analysis 
Vulnerability $=(0.4 \times$ social vulnerability score $)+(0.25$ $\times$ economic vulnerability score $)+(0.25 \times$ physical vulnerability score $)+(0.1 \times$ environmental vulnerability score) (3)

\section{Result dan Discussion}

\subsection{Result}

\subsubsection{Social vulnerability}

The social vulnerability in this study consists of population density with a weight of $60 \%$, the gender ratio of $10 \%$, age group ratio of $10 \%$, disability ratio of $10 \%$, and the low-income ratio of $10 \%$. Population density has the highest weight because the population is the subject most affected by the disaster. Data for each parameter was obtained from the Central Bureau of Statistics Pemalang Regency and the Indonesian Geospatial Information Agency.

The population density was calculated based on data obtained from the Central Bureau of Statistics Pemalang Regency and village administrative area data obtained from the Indonesian Geospatial Information Agency. The gender ratio is the ratio of the female population to the total population in an administrative area. The data were obtained from the Central Bureau of Statistics Pemalang Regency. The age group ratio in this study was the age group that is prone to hazards or disasters, namely the population aged 0-4-year-old and the population aged $\geq 65$-year-old. The proportion of persons with disabilities in this study was categorized into several types, namely disabilities, deaf and speech impaired, blind, multiple disabilities, mental disabilities, and disabilities from chronic disease.

Furthermore, the ratio of poor people used in this study was a standard according to the Indonesian National Family Planning Coordinating Board. According to the the National Family Planning Coordinating Board, the criteria for low-income families are Pre-Prosperous Families and Prosperous Families 1. The analysis results using the average deviation, standard deviation, scoring, and weighting indicated that the downstream Comal watershed area was dominated by a very high level of vulnerability to river floods (Table 3 ).

Table 2. The social vulnerability levels

\begin{tabular}{|c|c|r|r|}
\hline Vulnerability & \multirow{2}{*}{$\begin{array}{c}\text { Number } \\
\text { level }\end{array}$} & \multicolumn{2}{|c|}{ Large } \\
\cline { 3 - 4 } & Villages & Hectare & $\begin{array}{c}\text { Percent } \\
(\%)\end{array}$ \\
\hline Very high & 37 & $8,527.66$ & 39.12 \\
\hline High & 9 & $4,063.70$ & 18.64 \\
\hline Moderate & 10 & $6,768.17$ & 31.04 \\
\hline Low & 3 & $2,442.22$ & 11.20 \\
\hline Total & 59 & $21,801.75$ & 100.00 \\
\hline
\end{tabular}

Source: Data analysis

\subsubsection{Economic vulnerability}

Economic vulnerability in this study included the productive land area with a weight of $60 \%$ and the number of Economic Facilities 40\%. The productive land in the downstream Comal watershed was used as gardens/plantations, shrimp ponds, fishponds, wetland agricultural land (paddy fields), and dryland agriculture (moor/fields) with the primary commodities of rice, long beans, cassava, jasmine, maize, bitter melon, and chilies. The area of productive land was obtained from the interpretation of SPOT 5 High-Resolution Satellite Imagery, whose accuracy has been tested by field survey. Furthermore, the second parameter (element at risk) was the number of economic facilities. The economic facilities in this study include the number of markets, industries, hotels, shops, or stalls. These data were obtained from the Central Bureau of Statistics Pemalang Regency.

The results of data analysis showed that the low vulnerable class dominated the level of economic vulnerability to river flooding in the downstream Comal watershed with 27 villages (Table 4). It was influenced by the productive land area and the low number of economic facilities. Furthermore, economic vulnerability with high and very high vulnerable levels was not very dominant because of the influence of the weight of the productive land area parameter, which was more prevalent than the number of economic facilities.

Table 3. The economic vulnerability levels

\begin{tabular}{|c|c|c|c|}
\hline \multirow{2}{*}{$\begin{array}{c}\text { Vulnerability } \\
\text { level }\end{array}$} & \multirow{2}{*}{$\begin{array}{c}\text { Number } \\
\text { of } \\
\text { Villages }\end{array}$} & \multicolumn{2}{|c|}{ Large } \\
\hline & & Hectare & $\begin{array}{c}\text { Percent } \\
(\%)\end{array}$ \\
\hline Very high & 4 & $3,650.79$ & 16.75 \\
\hline High & 14 & $10,809.40$ & 49.58 \\
\hline Moderate & 5 & $1,762.43$ & 8.08 \\
\hline Low & 28 & $5,579.13$ & 25.59 \\
\hline Total & 59 & $21,801.75$ & 100.00 \\
\hline
\end{tabular}

Source: Data analysis

\subsubsection{Physical vulnerability}

The Physical vulnerabilities in this study consist of settlement density with a weight of $40 \%$, number of critical and public facilities by $30 \%$, and road length by $30 \%$. Settlement density is obtained from the number of houses in one village (unit) divided by village area (hectares). The number of settlements, critical facilities, and public facilities were obtained from the Central Bureau of Statistics Pemalang Regency. At the same time, the road length data was obtained from the visual interpretation of topographic maps and field surveys.

The density of settlements includes permanent, semi-permanent, and non-permanent houses [22]. At the same time, the number of public and critical facilities contained places of worship, schools, and health service infrastructures. Furthermore, the length of the road was the length of all the streets of the various road classes in the research location. The analysis results indicated that the level of the physical vulnerability to river flooding in the downstream Comal Watershed consisted of four vulnerability levels which was dominated by very high vulnerable levels (Table 5). 
Table 4. The physical vulnerability levels

\begin{tabular}{|c|c|r|r|}
\hline Vulnerability & \multirow{2}{*}{$\begin{array}{c}\text { Number } \\
\text { level }\end{array}$} & \multicolumn{2}{|c|}{ Large } \\
\cline { 3 - 4 } & Villages & Hectare & \multicolumn{1}{|c|}{$\begin{array}{c}\text { Percent } \\
(\%)\end{array}$} \\
\hline Very high & 27 & $8,553.55$ & 39.24 \\
\hline High & 23 & $9,429.73$ & 43.25 \\
\hline Moderate & 8 & $3,292.37$ & 15.10 \\
\hline Low & 1 & 526.10 & 2.41 \\
\hline Total & 59 & $21,801.75$ & 100.00 \\
\hline
\end{tabular}

Source: Data analysis

\subsubsection{Ecological (environmental) vulnerability}

In this study, environmental vulnerability included parameters (element at risk) of forest area with a weight of $70 \%$, bush $/$ shrubs by $10 \%$, and swamp area by $10 \%$. The forests in the research location consisted of community forests, state forests, and mangrove forests. The community forest is state-owned land managed by the local community, while the state forest is a forest that is owned and operated by the state. Mangrove forest is a forest with typical plants in tidal areas. These data were obtained from the SPOT 5 satellite imagery interpretation results that had been tested for accuracy through a field survey. Moreover, the level of environmental vulnerability to the Comal River flood was dominated by the very low vulnerable level. It was due to not all the parameters of the environmental vulnerabilities that exist in all villages (Table 6).

Table 5. The ecological (environment) vulnerability levels

\begin{tabular}{|c|c|r|r|}
\hline Vulnerability & \multirow{2}{*}{$\begin{array}{c}\text { Number } \\
\text { level }\end{array}$} & \multicolumn{2}{|c|}{ Lorge } \\
\cline { 3 - 4 } & Villages & Hectare & \multicolumn{1}{|c|}{$\begin{array}{c}\text { Percent } \\
(\%)\end{array}$} \\
\hline High & 5 & $3,817.19$ & 17.51 \\
\hline Moderate & 1 & 427.86 & 1.96 \\
\hline Low & 1 & $1,051.07$ & 4.82 \\
\hline Very low & 52 & $16,505.63$ & 75.71 \\
\hline Total & 59 & $21,801.75$ & 100.00 \\
\hline
\end{tabular}

Source: Data analysis

\subsubsection{The level of vulnerability toward the Comal River flood}

The level of vulnerability to the Comal River flooding was obtained from the sum of the weights of each vulnerability variable, namely the social, economic, physical, and ecology (environmental) variables (Fig. 2 ). The social variables have a weight of $40 \%$, economic variables $25 \%$, physical variables $25 \%$, and environmental variables $10 \%$. The weight of each of these variables is based on the Head of the Indonesian National Disaster Management Agency Regulation 2012 [9]. The results showed the level of vulnerability toward the Comal River flooding consisted of four vulnerability levels and was dominated by high vulnerable levels (Table 7).
Table 6. The level of vulnerability toward the Comal river flood

\begin{tabular}{|c|c|c|c|}
\hline \multirow{2}{*}{$\begin{array}{c}\text { Vulnerability } \\
\text { level }\end{array}$} & \multirow{2}{*}{$\begin{array}{c}\text { Number } \\
\text { of } \\
\text { Villages }\end{array}$} & \multicolumn{2}{|c|}{ Large } \\
\hline & & Hectare & $\begin{array}{c}\text { Percent } \\
(\%)\end{array}$ \\
\hline Very high & 3 & $1,670.39$ & 7.66 \\
\hline High & 29 & $8,773.11$ & 40.24 \\
\hline Moderate & 26 & $10,832.15$ & 49.69 \\
\hline Low & 1 & 526.10 & 2.41 \\
\hline Total & 59 & $21,801.75$ & 100.00 \\
\hline
\end{tabular}

Source: Data analysis

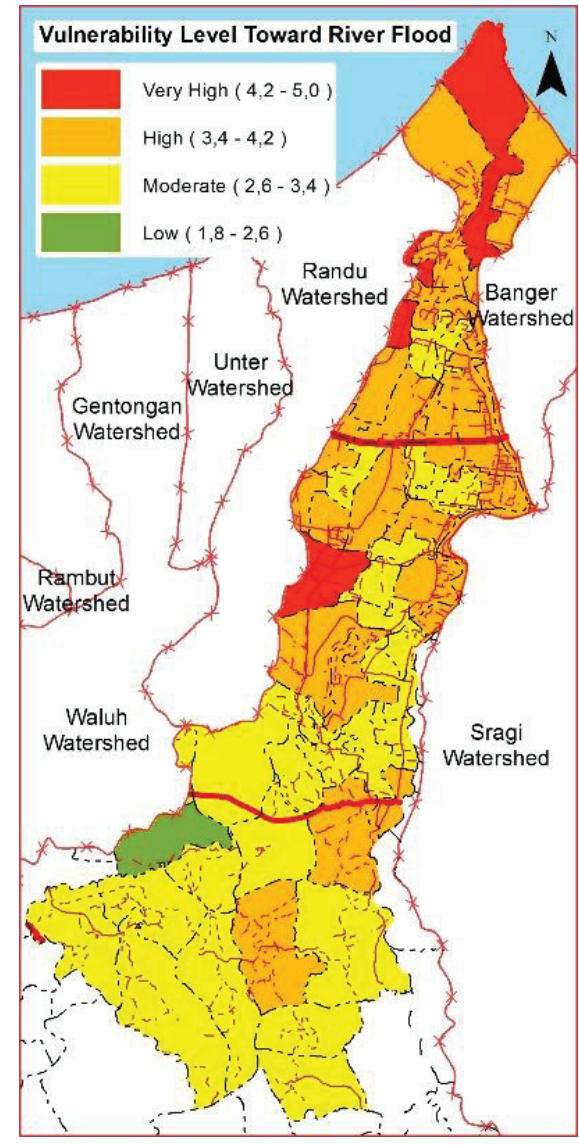

Figure 2. The vulnerability toward Comal river flooding

\subsection{Discussion}

The Research conducted by [3] used landuse as a parameter of vulnerability. [1] used the poor, gender, and education level as the parameters, while [23][24] formulated social vulnerability parameters including Poverty, Gender disparities and low educational attainment, access to drinking water and health hazards, rapid population growth as well as transboundary insecurity. Moreover, the differences in data use will affect the outcome of social vulnerability. The more variations in population data used, the more accurate the results will be in describing conditions in the field [7]. 
Therefore, this study used the population parameters by $[1,9,25]$ because it was considered to represent all aspects related to the population.

The most dominant social vulnerability level in the downstream Comal watershed was the very high and high vulnerable level. The high social vulnerability to Comal River flooding describes the lack of capacity of the population in dealing with floods. Therefore, socialization and simulations of river flooding disasters were needed to increase people's understanding of flood disasters. Furthermore, the role of the local government was very much needed because the increased knowledge of the population about flood disasters will increase their capacity in dealing with flood disasters [13,26-29].

The parameter of economic vulnerability in this study significantly affects the condition of the population. The assumption used was that the income of people who work as farmers, fishpond farmers, traders, service entrepreneurs will be disrupted. It happened when the floods hit, and they cannot run the kind of economic activity under normal circumstances. This means that no income was earned, or it can even be assumed that losses were due to damaged rice fields, damaged ponds, and difficulty selling merchandise and services due to flooding. It was very different from residents who work as state civil servants, bank employees, police, Indonesian national army, or other professions with regular income each month. Furthermore, residents with this profession will continue to earn income as in normal circumstances without a disaster even though the settlement or place of work of residents of that profession is affected by flooding.

The parameters in physical vulnerability were the facilities needed and used by the population in their daily life. Therefore, the higher the frequency and intensity of floods that hit these parameters, the activity of the population will also be disrupted and even completely paralyzed. One of the most dominant parameters was the density of houses/settlements. The higher the population density, the denser the settlement [30]. The high density of population and settlements causes new needs to emerge. These needs include housing, economic, social, and educational facilities. The facilities and infrastructure to meet these needs appear along with the development of these areas. Very high and high vulnerable levels dominated the level of physical vulnerability to flooding in the downstream Comal watershed. Very high and high vulnerable levels dominate the sum of weights for all parameters of physical vulnerability to the Comal River Flooding. It was very reasonable when viewed from the parameters that make up physical vulnerability because almost all villages in the downstream Comal watershed have developed into dense settlements.

The parameters in ecological (environmental) vulnerability were determined based on their natural function. If these parameters were affected by flooding, the natural function and ecosystem in the area will be disturbed or even damaged. Environmental variables included natural assets that can reduce the negative impact of disasters. If environmental variables are disturbed or damaged, it will take a very long time to rehabilitate and restore them to their original condition. Therefore, the deeper the vulnerability assessment, the wider the parameters of environmental vulnerability in an area. This will affect the high level of vulnerability of the region.

Protected forests, mangrove forests, and swamps are habitats for a wide variety of flora and fauna, while production forests have an economic function for their managers. Protected forests, production forests, mangrove forests, shrubs also have other natural parts to slow down the flow or velocity of water flow when a flood occurs and hold the inherent material washed away when the surge occurs. Therefore, if a flood hits and causes mangrove forest damage, it will cause huge losses, not only from an economic perspective but also from an ecological perspective. This study used the vulnerability variable following the Head of the Indonesian National Disaster Management Agency Regulation 2012 [9].

Very low vulnerable classes dominated the level of environmental vulnerability to flooding in the downstream Comal watershed. This was because not all ecological vulnerability parameters were found in all villages. Therefore, the environmental vulnerability classes in the downstream Comal watershed were at the same level. Only a few villages had these parameters, and this was due to the conversion of land functions and different characteristics of the area. Swamps and mangrove forests were only found around the mouth of the Comal River, namely in the villages of Mojo and Kendaldoyong. The forest was located in the village in the Bodeh Subdistrict area, one of the areas with the highest elevation in the downstream Comal watershed.

Very high and medium vulnerable classes dominated regional vulnerability to flooding in the downstream Comal watershed. This was because the social and physical vulnerability had a dominant influence over economic and environmental vulnerability. It was because not all parameters of economic and environmental vulnerability exist in all villages. Areas with a very high vulnerability class consisted of Mojo and Kendaldoyong Villages. In Mojo and Kendaldoyong Village, there were all the parameters of vulnerability, especially environmental vulnerability, such as forests and swamps that were not found in other villages. Meanwhile, in Kendalsari Village, although it was a very high vulnerable class, the dominant variables were social, economic, and physical vulnerability.

\section{Conclusion}

The vulnerability to Comal River flooding were classified into four classes of vulnerability, namely very high, high, medium, and low. The variables used in determining total vulnerability are social, economic, physical, and ecological (environmental) vulnerability. Each variable consisted of various parameters adjusted to the type of vulnerability variable and the characteristics of the research location. The total vulnerability to Comal river flooding in the downstream Comal watershed was dominated by the moderate vulnerable class of $10,832.15$ hectares $(49.69 \%)$ and distributed in 26 villages. This was because the area was 
an area with fertile and flat topography, so that it has developed into a center of government, settlement, economic center, and education center. Therefore, it needs efforts to increase community capacity and disaster mitigation planning to reduce the impact of disasters. This was because the high level of vulnerability also covered a large area, namely 8,773.11 hectares (40.24\%), and was distributed across 29 villages. Furthermore, although the vulnerability variables were determined based on the Head of the Indonesian National Disaster Management Agency Regulation 2012, the determination of the parameters of each variable has not been carried out by a more indepth method. It is hoped that further research can carry out a more in-depth analysis so that the vulnerability analysis results are more accurate. Financial support for this study was provided by the Indonesian ministry of education and culture.

\section{References}

1. E. Mavhura, A. Collins, and P. P. Bongo, Disaster Prev. Manag. 26, 41 (2017)

2. S. Mahato, S. Pal, S. Talukdar, T. Kanti Saha, and P. Mandal, Geosci. Front. 12, (2020)

3. W. Chen, X. Wang, S. Deng, C. Liu, H. Xie, and Y. Zhu, J. Hydrol. 575, 454 (2019)

4. S. Thapa, A. Shrestha, S. Lamichhane, R. Adhikari, and D. Gautam, J. Hydrol. Reg. Stud. 30, 100704 (2020)

5. H. Bang, L. Miles, and R. Gordon, Foresight 21, 266 (2019)

6. A. Dewan, Flood in a Megacity: Geospatial Techniques in Assessing Hazards, Risk and Vulnerability (2013)

7. H. Chang, A. Pallathadka, J. Sauer, N. Grimm, R. Zimmerman, C. Cheng, D. Iwaniec, Y. Kim, R. Lloyd, T. McPhearson, B. Rosenzweig, T. Troxler, C. Welty, R. Brenner, and P. Herreros, Sustain. Cities Soc. 68, 102786 (2021)

8. R. Jha and H. Gundimeda, Int. J. Disaster Risk Reduct. 35, 101074 (2019)

9. the Indonesian National Disaster Management Agency, 62 (2012)

10. UNISDR, (2009)

11. C. J. Van Westen, D. Alkema, M. C. J. Damen, N. Kerle, and N. C. Kingma, Risk City Exercise Book (United Nations University - ITC School on Disaster Geoinformation Management, Twente, 2011)

12. S. Kumpulainen, Spec. Pap. Geol. Surv. Finl. 65 (2006)

13. ADPC, Urban Governance and Community Resilience Guides: Risk Assessment in Cities (2010)

14. M. Imran, K. Sumra, S. A. Mahmood, and F. Sajjad, Int. J. Disaster Risk Reduct. 41, 101288 (2019)

15. H. B. Abbas and J. K. Routray, Disaster Prev. Manag. 23, 395 (2014)

16. A. El-Zein, T. Ahmed, and F. Tonmoy, Ecol. Indic. 121, 106988 (2021)

17. E. A. Adams and H. Nyantakyi-Frimpong, Heal.
Place 67, 102500 (2021)

18. T. Sarmah, S. Das, A. Narendr, and D. B. Aithal, Int. J. Disaster Risk Reduct. 50, 101659 (2020)

19. V. S. A. Hendrawan and D. Komori, Int. J. Disaster Risk Reduct. 54, 102058 (2021)

20. M. Musiyam, Int. J. GEOMATE 19, (2020)

21. The Republic of Indonesia Ministry of Forestry, Decree of The Minister of Forestry of The Republic of Indonesia Number 328 Menhut-II 2009 Concerning Determination of Priority Watersheds in the Framework of the Medium Term Development Plan (RPJM) 2010-2014 (Indonesia, 2009), p. 8

22. H. Desalegn and A. Mulu, Heliyon 6, (2021)

23. M. A. A. Hoque, S. Phinn, C. Roelfsema, and I. Childs, Appl. Geogr. 98, 22 (2018)

24. H. Bang, (2009)

25. A. Karunarathne and G. Lee, Int. J. Disaster Risk Reduct. 49, 101679 (2020)

26. M. A. Marfai, A. Cahyadi, H. Fatchurohman, F. S. C. Rosaji, and Y. A. Wibowo, IOP Conf. Ser. Earth Environ. Sci. 256, (2019)

27. M. A. Marfai, Sunarto, N. Khakim, H. Fatchurohman, A. Cahyadi, Y. A. Wibowo, and F. S. C. Rosaji, in E3S Web Conf. (2019)

28. F. Ullah, S. Azmat, S. A. Ali Shah, S. E. Saqib, M. Yaseen, S. Muhammad, and Haider, Int. J. Disaster Risk Reduct. 52, 101967 (2021)

29. N. Pricope, J. Halls, and L. Rosul, J. Environ. Manage. 237, 387 (2019)

30. A. K. Christian, B. D. Dovie, W. Akpalu, and S. N. A. Codjoe, Urban Clim. 35, 100759 (2021) 